\title{
Finite Elements Multiphysics Investigation of Thermoelectric Systems for Electricity and Cooling Generation
}

\author{
Wiem Nasri $^{1}$, R. Djebali ${ }^{2}$, S. Dhaoui ${ }^{3}$, S. Abboudi ${ }^{4}$, H. Kharroubi ${ }^{1}$ \\ ${ }^{1}$ ESIM, 9070, Medjez El Bab-Tunisia \\ ${ }^{2}$ ISLAI Béja, Univ. Jendouba, Av. Environment, Béja 9000, Tunisia \\ ${ }^{3}$ Department of Electrical Engineering, ISET of Béja, Tunisia \\ ${ }^{4}$ Lab. ICB-COMM- site UTBM, 90010 Belfort,, France
}

\author{
*Corresponding Author: R. Djebali, ISLAI Béja, Univ. Jendouba, Av. Environment, Béja 9000, Tunisia
}

\begin{abstract}
This paper aims to present a numerical simulation study based on finite elements method of the thermo-electro-mechanical behavior for a thermoelectric module (TEM) under operating conditions. The main goal is to scrutinize and find explanations for module loss of performance and reliability. Both of the electricity and cooling generation and the thermo mechanical behavior are analyzed. Under a constant heat flux of energy density close to $25.9 \mathrm{~kW} / \mathrm{m}^{2}$, a maximum temperature and deformation of $219{ }^{\circ} \mathrm{C}$ and $11.7 \mu \mathrm{m}$ are obtained for the tested module. The temperature difference increase between upper and lower surface of the module has positive effect on the released power. The heat transfer coefficient value of the cooling fluid used for the module lower surface is found characterizing the water. Moreover, in open circuit, the tension increases as the length of the leg increases. Finally, the cooling capacity (Peltier effect) and the coefficient of performance COP of multi-stages module are investigated. For single stage module, the COP was maximum for a current intensity close to $0.4 \mathrm{~A}$ and COP $>0.8$ between [0.35A, 0.45A] and the increase of the stages number resulted in a decrease of the COP.
\end{abstract}

Keywords: Thermoelectric modules, electricity and cooling generation, thermo-electro-mechanical behavior, parametric study.

\section{INTRODUCTION}

Multiphysics modeling is one of the most challenging problems in numerical investigations mainly with the technological development and the improvement of numerical codes allows several computations [1-4]. The goal is to have more realistic theoretical studies and not neglect the effects of some phenomena even if minority.

Thermoelectricity is taking off at the moment by essentially improving energy efficiency. Indeed, thermoelectricity represents a very interesting source of energy as it is known as renewable and green. Not only is it a concept of development, but rather a vector of international development. Although it has been discovered for a century, this new non-polluting energy source is considered an inevitable strategy to increase current energy, sustainable development and environmental challenges.

These devices operate in a reversible manner. Not only do they produce electricity, they also function as a heat pump or cold source. However, unusual failures and decreased efficiency of thermoelectric (TE) systems appear for unprofitable operating times. These malfunctions (total or partial) are typically related to thermomechanical overload or strain.

Currently, many studies have been conducted to improve the efficiency and reliability of TE systems. This research is based on several criteria, such as TE properties of the materials and the flexibility of the design of TE systems. In fact, the optimal conversion of thermal energy into electricity requires materials optimized over a wide temperature range, a safe design and controlled conditions of use.

Alibadi and al. (2014) [5] focused their study on using TE devices for cryogenic medical treatment. They analyzed the performance of the single stage and multistage TE devices by means of COMSOL Multiphysics. They have concluded that implementation of multistage Peltier modules can generate very low temperature of $-70^{\circ} \mathrm{C}$ for cancerous tissue ablation. 
Finite Elements Multiphysics Investigation of Thermoelectric Systems for Electricity and Cooling Generation

Suzuki et al. (2012) [6] have performed a dimensional analysis of TEM under constant heat flux; and using a combination of the FV and original simultaneous solver. It has been shown that longer and thicker TEMs can generate more electric power. It has been demonstrated also that the electrical contact resistance in the TEM causes an impedance shift such that the optimal external resistance becomes larger than the internal resistance.

Kraemer et al. (2012) [7] have introduced simplified model and an optimization methodology for terrestrial solar thermoelectric generators (STEGs). Authors showed that the TE elements in STEGs can be scaled in size without affecting the device performance, even for temperature-dependent properties of the TE material and the solar absorber. The proposed model is economical and offers the advantage to adjust the electric current throughout the day to favor either electricity or hot water production.

\begin{tabular}{|c|c|}
\hline Nomenclature & \\
\hline D: Density vector of the electrical flux & $\sigma_{\text {equiv }}:$ Equivalent constraint \\
\hline E: Electric field & $\lambda$ : Lamé coefficient \\
\hline J: Electric current density vector & $\mu=\mathrm{G}:$ Coulomb module \\
\hline q: Heat flow vector & v: Poisson's ratio \\
\hline$[\lambda]$ : Thermal conductivity (W/m.K) & I: Intensity of electric current (A) \\
\hline$[\pi]$ : Matrix of Peltier coefficient $[\pi]=\mathrm{T}[\alpha]$ & J: Joule effect \\
\hline$[\boldsymbol{\alpha}]$ : Seebeck coefficient matrix & C: Calorific capacity (J / Kg.K) \\
\hline$[\varepsilon]$ : Matrix of relative permittivity & K: Thermal conductance $(\mathrm{W} / \mathrm{K})$ \\
\hline$\overline{\bar{\sigma}}$ : Constraint matrix & $E$ : Young's modulus \\
\hline$\overline{\bar{\varepsilon}}$ : Matrix of deformations & T: Absolute temperature (K) \\
\hline$\overline{\bar{I}}$ : Identity matrix & $\mathrm{T}_{\mathrm{c}}$ : Absolute temperature of the cold face $(\mathrm{K})$ \\
\hline$\rho:$ Density $\left(\mathrm{Kg} / \mathrm{m}^{3}\right)$ & $\mathrm{T}_{\mathrm{h}}$ : Absolute temperature of the hot face $(\mathrm{K})$ \\
\hline$\Phi:$ Specific flow of heat sources $\left(\mathrm{W} / \mathrm{m}^{3}\right)$ & $s:$ Safety coefficient \\
\hline$\varphi$ : Rate of heat production & $\mathrm{Q}_{\mathrm{c}}$ : Cooling capacity/ pumped power at cold side $(\mathrm{W})$ \\
\hline$\varepsilon:$ Relative permittivity & $\mathrm{Q}_{\mathrm{h}}$ : Heat emitted from the warm side $(\mathrm{W})$ \\
\hline$\beta$ : Coefficient of linear thermal expansion & P: Power applied to the module \\
\hline$\alpha$ : Seebeck coefficient & R: Electrical resistance $(\Omega)$ \\
\hline$\sigma_{\theta}:$ Limit of elasticity & V: voltage / tension $(\mathrm{V})$ \\
\hline$\sigma$ : Electrical conductivity & COP: Coefficient of performance \\
\hline
\end{tabular}

Ziabari et al. (2012) [8] used an analytical and finite-element-analysis modeling to investigate the problem of reducing the interfacial shearing stress in a TEM structure. High temperature differences between the ceramic parts in thermo-electric modules (TEMs) used under high temperatures makes the TEMs vulnerable to high thermal stress leading to possible mechanical failures. The authors showed that the shearing stress can be strongly reduced by using thinner and longer legs and compliant interfacial materials.

Chen et al. (2014) [9] used a new theoretical method accounting for the temperature-dependent properties of the commercial TE material to investigate the performance of a thermal-concentrated solar TEG. An equivalent model was developed to simulate the real-sized TEG module and the power consumption for cooling the TEG module was evaluated using an analytical method. It has been concluded also that the cooling conditions play no role in the performance of the solar TEG when forced convection is encountered with a heat transfer coefficient $h$ greater than $500 \mathrm{~W} \cdot \mathrm{m}^{-2} \cdot \mathrm{K}^{-1}$. According to the new method, a larger and positive net output power can be achieved using water cooling for the solar TEG.

The present work present a multiphysics modeling and simulation study of TE systems for electricity generation (Seebeck effect) or cooling production (Peltier effect). As for the generation of electricity, the solar concentrator amplifies heat flux tens of times and TEM (conversion element) is faced to thermomechanical stresses due to thermal expansion which can exceed permissible load, which causes cracks that increase the thermal resistance (affecting performance) or splits (breaks) inducing system malfunction (affecting reliability). 
On cold days, the TE element or module is subjected to compression stresses due to thermal contraction. The daily and seasonal repetition of this behavior is a source of cyclic fatigue of the module. In addition, the system works at hundreds of degrees Celsius so that its thermophysical properties become strongly dependent on temperature. The study is therefore of high order complexity due to the coupling of several principles of physics. More details on the TEM (Seebeck and Peltier effects) uses and how does it work may be found in Wikipedia encyclopedia [10].

In this work, a FE modelling and simulation has been conducted. The deformation rate was explored for two Bi2Te 3 two-legs of size $1 \times 1 \times 5.8 \mathrm{~mm} 3$ with a space of $2 \mathrm{~mm}$ in order to confirm the existence of polycyclic fatigue problem under the solar radiation effect. A parametric study has been carried out on a commercialized industrial model to quantify its performances to generate electricity and cooling under real solar radiation. For the electric generation, the tested factors are the current intensity, the heat transfer coefficient $h$ $(\mathrm{W} / \mathrm{m} 2 / \mathrm{K})$, the length of TE elements under constant heat flux and the temperature difference between the bottom and the ceiling of the TEM. For cooling production, multistages TEM are tested and the thermal management will be presented.

\section{Modeling BASIS}

The properties of the TE material, namely the Bismuth Telluride III, depend on the temperature meaning means that the physical phenomena involved are fully coupled. The three physical phenomena are: conduction of electric current, heat transfer with production of heat or cooling, and structural constraints (mechanical stresses and strain) which are due to repetitive thermal expansioncontraction cycles.

\subsection{Governing Equations}

\subsubsection{Thermoelectric Equations}

The behavior of a TE material is described by the following governing equations which couple the thermal and electrical fields. For accurate modeling of the TE systems, the Joule effect must be taken into account [11]. The governing equations are written as follows [11]:

$\rho C \frac{\partial T}{\partial t}+\nabla_{q}=\phi$

$\nabla\left(J+\frac{\partial D}{\partial t}\right)=0$

$E=-\nabla \varphi$

The constitutive equations are given by [10]:

$q=[\pi] J-[\lambda] \nabla T$

$I=[\sigma](E-[\alpha] \nabla T)$

$D=[\varepsilon] E$

is the Therefore, the equations of the electric field and thermal couples in local form are given in the following form:

$-\vec{\nabla} \cdot\left(\left(\sigma \alpha^{2} T+\lambda\right) \vec{V} T+\sigma \alpha T \vec{V} V\right)=\sigma\left((\vec{V} V)^{2}+\alpha \vec{\nabla} T \vec{V} V\right)$

$\vec{\nabla} \cdot(\sigma \alpha \vec{\nabla} T)+\vec{\nabla} \cdot(\alpha \vec{V} V)=0$

\subsubsection{Implementation in COMSOL}

In such complex multi-physic problem, numerical simulation becomes of practical use. COMSOL Multiphysics is one of the most popular and powerful tool among a large variety available for engineering and industrial applications. This tool is employed to tackle multi-physic problems based on finite element approach using set elementary solvers that can be coupled in various ways. In the 
present study, the governing equations as well as initial and boundary conditions are numerically implemented by means the COMSOL Multiphysics finite-elements software.

COMSOL Multiphysics allows integrating arbitrary equations to the partial derivatives (PDE) of the variable of a certain field of interest for one to three dimensional regions [11]. Increasing the temperature, results in local expansion of the material. This expansion can play an important role in mechanical and residual stresses and one can notice this variation over time also. For such a reason, thermo-mechanical coupling should be taken into account in our study.

This notation follows the documentation of the COMSOL Multiphysics and with parameters $\alpha, \sigma$ and $\lambda$ appearing in equations (4-8) but with other physical meanings.

$c_{a} \frac{\partial^{2} u}{\partial t^{2}}+d_{a} \frac{\partial u}{\partial t}+\nabla \cdot(-c \nabla \boldsymbol{u}-\alpha \boldsymbol{u}+\gamma)+\beta \cdot \nabla \boldsymbol{u}+a \boldsymbol{u}=f \quad$ in $\Omega$

n. $(-c \nabla \boldsymbol{u}-\alpha \boldsymbol{u}+\gamma)+q \boldsymbol{u}=g-h^{T} \mu$ in $\partial \Omega$

$h \boldsymbol{u}=r \quad$ in $\partial \Omega$

In static mode, we will simplify terms in (9) and (10), and then one obtains:

$\nabla \cdot(-c \nabla u)=f \quad$ in $\Omega$

n. $(-c \nabla u)=g-h^{T} \mu$ in $\partial \Omega$

With the variable of the vector field $\vec{u}$ values: $\vec{u}\left(\begin{array}{l}T \\ V\end{array}\right)$ and the coefficients in (9) are:

$\left\{\begin{array}{c}c=\left(\begin{array}{cc}\lambda+\sigma \alpha^{2} T & \sigma \alpha T \\ \sigma \alpha & \sigma\end{array}\right) \\ f=\left(\begin{array}{c}\left.(\sigma V)^{2}+\alpha \overrightarrow{\nabla T V V}\right) \\ 0 \\ d=\left(\begin{array}{c}\rho c \\ 0\end{array}\right)\end{array}\right)\end{array}\right.$

The other coefficients in equation (13) are zero for static calculations.

\subsubsection{Thermo Mechanical Coupling}

Increasing the temperature, results in local expansion of the material. This expansion can play an important role in mechanical and residual stresses and one can notice this variation over time also. For such a reason, thermo mechanical coupling should be taken into account in our study.

The constitutive equations may be written in the following form:

$\overline{\bar{\sigma}}=\overline{\sigma^{0}}+2 \mu \overline{\bar{\varepsilon}}+\left(\lambda \operatorname{trace}(\bar{\varepsilon})-\beta\left(T-T_{0}\right)\right) \overline{\bar{I}}$

Where

$\sigma_{i j}=2 \mu \varepsilon_{i j}+\lambda \theta \delta_{i j}$

$=\frac{E}{1+v} \varepsilon_{i j} \frac{v E}{(1+v)(1-2 v)} \varepsilon_{k k} \delta_{i j}$

And

$\left\{\begin{array}{l}\mu=\frac{E}{2(1+v)}=G, \lambda=\frac{v E}{(1+v)(1-2 v)} \\ v=\frac{\lambda}{2(\lambda+\mu)}, \alpha=\frac{\beta}{3 \lambda+2 \mu}, s=\frac{\sigma_{e}}{\sigma_{\text {equiv }}}\end{array}\right.$

\subsection{Materials}

TE materials are characterized by three parameters: The Seebeck coefficient, the electrical conductivity and the thermal conductivity. The properties of the materials are already available in the COMSOL Multiphysics materials library. However the given properties of Bismuth Telluride in literature differ slightly; and we will use the values used by Jeagle [11] and summarized in Table (1).

Some properties of Alumina $\mathrm{Al}_{2} \mathrm{O}_{3}$ are summarized in Table 2 and the library values of the COMSOL Multiphysics software are used. 
Finite Elements Multiphysics Investigation of Thermoelectric Systems for Electricity and Cooling Generation

Table1. Properties of materials for the semiconductor: Bismuth telluride and electrode: Copper [11].

\begin{tabular}{|c|c|c|}
\hline Properties & Thermoelectric material & Electrode : Copper \\
\hline Thermal conductivity [W/ $(\mathrm{m} . \mathrm{K})]$ & 1.6 & 350 \\
\hline Density $\left[\mathrm{Kg} / \mathrm{m}^{2}\right]$ & 7740 & 8920 \\
\hline Heat capacity [J/(Kg.K)] & 154.4 & 385 \\
\hline Electric conductivity [S/m] & $1.1 \mathrm{e} 5$ & $5.9 \mathrm{e} 8$ \\
\hline Relative permittivity & 1 & $>250000$ \\
\hline Seebeck coefficient [V/K] & $\mathrm{P}: 2 \mathrm{e}-4 / \mathrm{N}:-2 \mathrm{e}-4$ & $6.5 \mathrm{e}-6$ \\
\hline Young's Modulus [GPa] & $11.7-25.7$ & 0.34 \\
\hline Poisson's ratio & 0.241 & $16.5 \mathrm{e}-6$ \\
\hline Thermal expansion coefficient $[1 / \mathrm{K}]$ & $14.4 \mathrm{e}-6$ & \\
\hline
\end{tabular}

Table2. Properties of Alumina $\mathrm{Al}_{2} \mathrm{O}_{3}$

\begin{tabular}{|c|c|c|c|}
\hline Properties & Symbol & Value & Unity \\
\hline Thermal conductivity & $\lambda$ & 35 & $\mathrm{~W} /(\mathrm{m} . \mathrm{k})$ \\
\hline Heat capacity & $\mathrm{Cp}$ & 730 & $\mathrm{~J} /(\mathrm{Kg} . \mathrm{K})$ \\
\hline Electrical conductivity & $\sigma$ & 0 & $\mathrm{~S} / \mathrm{m}$ \\
\hline Relative permittivity & $\varepsilon$ & 5.7 & 1 \\
\hline Seebeck coefficient & $\mathrm{S}$ & $>1 \mathrm{~m}$ & $\mathrm{~V} / \mathrm{K}$ \\
\hline Density & $\rho$ & 3965 & $\mathrm{Kg} / \mathrm{m}^{2}$ \\
\hline Coefficient of linear thermal expansion & $\alpha$ & $8.1 \mathrm{e}-6$ & $1 / \mathrm{K}$ \\
\hline Young's modulus & $\mathrm{E}$ & 400 & $\mathrm{GPa}$ \\
\hline Poisson's ratio & $v$ & 0.22 & 1 \\
\hline Max. temperature of use without load & $\mathrm{T}$ & 1700 & ${ }^{\circ} \mathrm{C}$ \\
\hline Limit of elasticity & $\mathrm{Re}$ & 275 & $\mathrm{MPa}$ \\
\hline
\end{tabular}
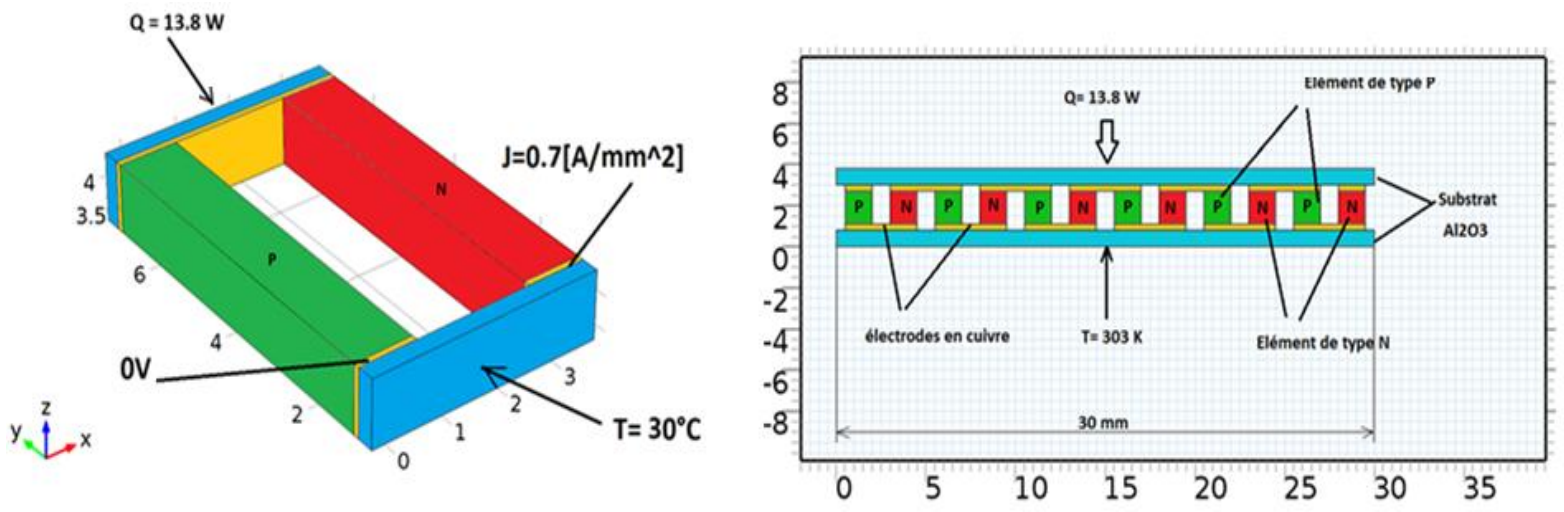

Figure1. Composition of the PN thermocouple (left) and of the GM200-71-14-16 thermoelectric generator (TEG) (right) and the applied boundary conditions according to Suzuki et al. [6]

\subsection{Models Description}

We have adopted two models. The first one is a simple PN thermocouple junction made of $\mathrm{Bi}_{2} \mathrm{Te}_{3}$ in contact with copper electrodes and $\mathrm{Al}_{2} \mathrm{O}_{3}$ Alumina substrates. The leg size of $\mathrm{Bi}_{2} \mathrm{Te}_{3}$ is $1 \times 1 \times 5.8 \mathrm{~mm}^{3}$ with a space of $2 \mathrm{~mm}$ between the two legs. The electrodes are of copper material with thickness $0.1 \mathrm{~mm}$ and the substrate with a thickness of $0.3 \mathrm{~mm}$. The second is the commercialized industrial model GM 200-71-41-16 (European thermodynamics [12], see Fig. (1)).

\subsection{Assumptions and Boundary Conditions}

The same conditions apply for the two models:

- The semiconductors are homogenous and isotropic.

- A current density $\mathrm{J}_{0}=0.7 \mathrm{~A}$ was applied to one of the electrodes while the other is maintained at OV.

- The lower substrate was maintained at $30^{\circ} \mathrm{C}$.

International Journal of Modern Studies in Mechanical Engineering (IJMSME) 
- A constant heat flux was applied to the other side of the substrate with value of $13.8 \mathrm{~W}$ corresponding to an energy density close to $25.9 \mathrm{~kW} / \mathrm{m}^{2}$.

- The lower side of the substrate was fixed.

- Adiabatic conditions on all other sides.

- Concerning the second model, the TE elements P and $\mathrm{N}$ are electrically connected in series and thermally in parallel.

The properties of the materials are taken from tables 1 and 2 mentioned above.

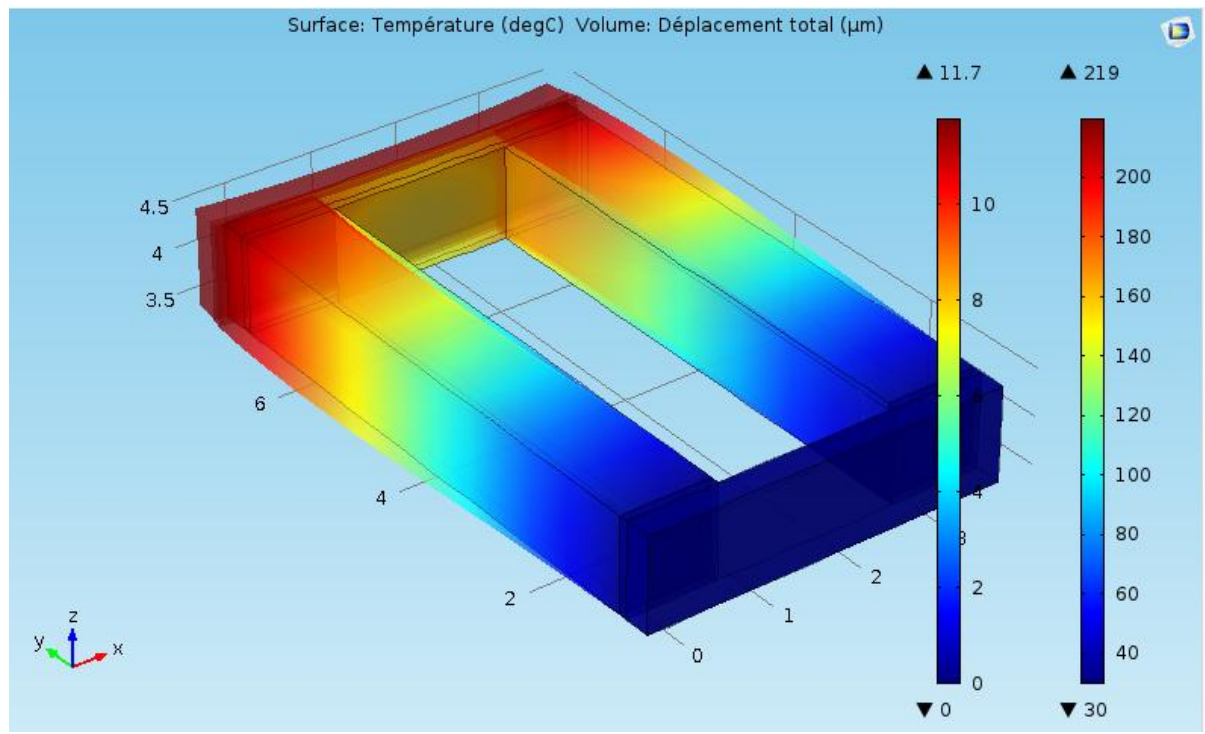

Figure2. Deformation due to thermal expansion for PN thermocouple

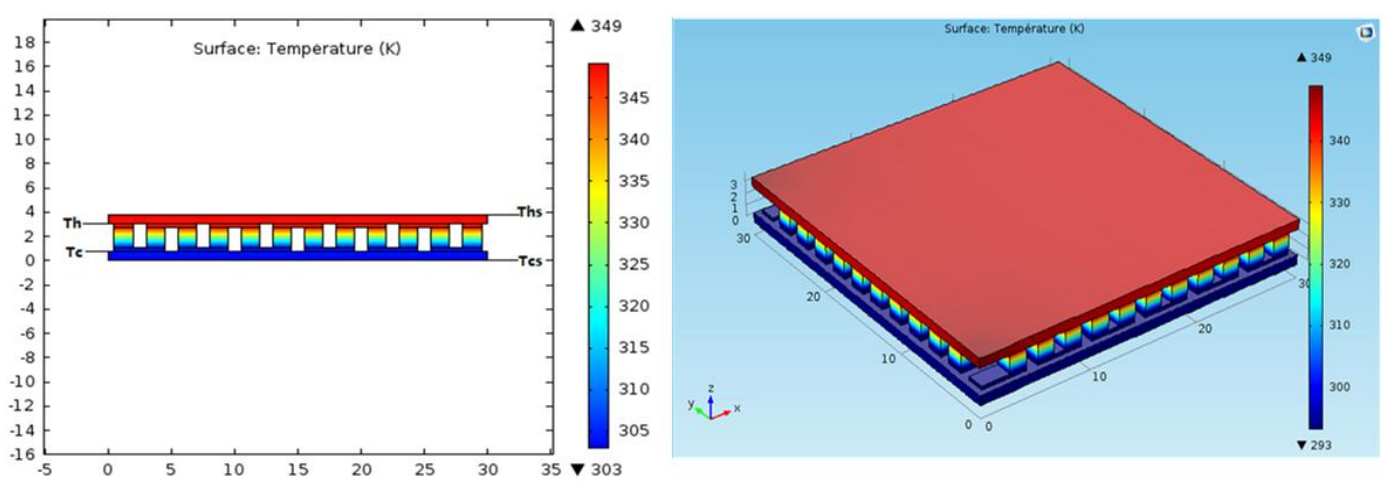

Figure3. Temperature distribution of a single stage Peltier GM-200-71-41-16

\section{RESULTS AND DISCUSSIONS}

\subsection{Thermoelectric Generation}

As it shown in Figure 2, the maximum temperature for the thermocouple is of the order of $219^{\circ} \mathrm{C}$. and the maximum deformation is close to 11.7 microm, this deformation is due to the thermal expansion. While for the solar TEG, the maximum $\mathrm{T}$ is close to $76^{\circ} \mathrm{C}$ (Fig. 3).In order to evaluate the performance of these devices, we need to analyze the influence of many parameters:

\subsubsection{Influence of the Intensity}

For the solar TEG, the temperatures at the terminals of the upper and lower substrates were marked, for different current intensities. It is noted that the temperatures of the lower alumina plate remain constant while the temperatures of the upper alumina plate decrease by increasing the current (Fig. 4).

This can be explained as follows: The voltage generated by the Seebeck effect due to the imposed temperature difference generates the current in the circuit. The latter is itself reflected by the Peltier effects which cool the hot terminal and warm the cold terminal. 
Finite Elements Multiphysics Investigation of Thermoelectric Systems for Electricity and Cooling Generation

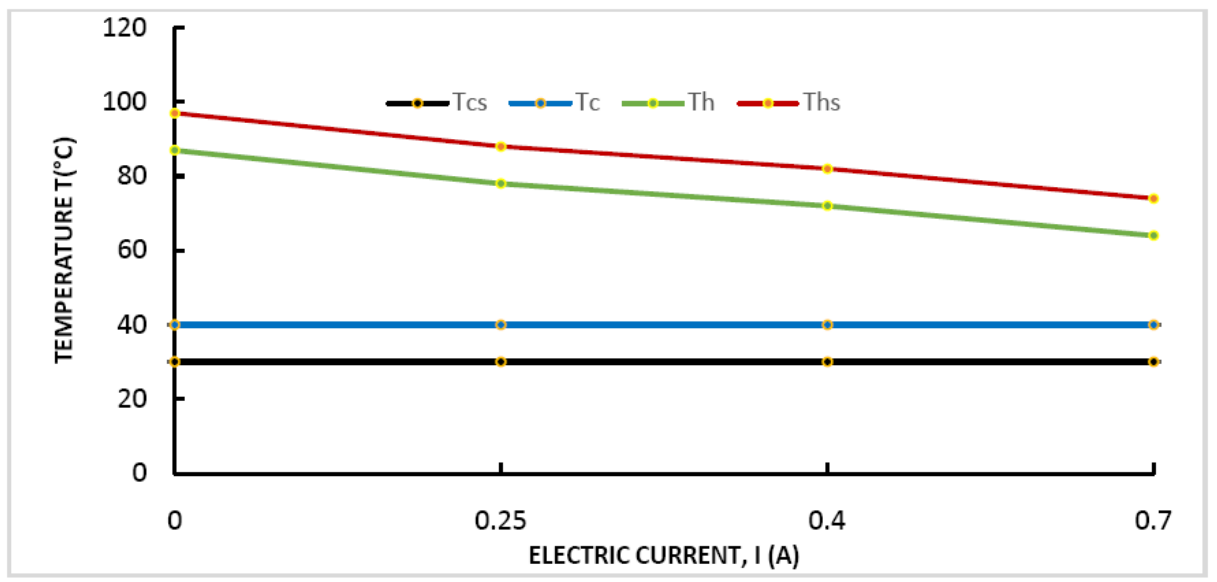

Figure4. Temperature variation vs electric current. Ths, Th,Tc and Tcs are defined in Figure 3.

\subsubsection{Distribution of Von Mises Stresses}

What we are most interested in, is the distribution of Von Mises stresses, from which we will decide how to control thermo mechanical stresses. The results show that for the solar TEG the maximum stress is in the order of $179 \mathrm{MPa}$, which does not exceed the allowable stress of the alumina $275 \mathrm{MPa}$, whereas for the thermocouple, it is of the order of $628 \mathrm{MPa}$ which exceeds the permissible stress of the alumina. The Figures (5 and 6) show the Von Mises stresses.

The simulation also reveals the limits of the design, as the module will not function properly if the stresses exceed the elastic limits. It is therefore preferable to cool to alleviate the stresses, however this also costs energy. For this purpose an attempt was made to reduce the temperature difference $\Delta \mathrm{T}$ and it was found that for a hot temperature of $150{ }^{\circ} \mathrm{C}$., the maximum stress of Von Mises is equal to $253 \mathrm{MPa}$ which is less than the permissible stress of the alumina.

\subsubsection{Risk of the Presence of Defects}

Another problem that may be encountered is the risk of the presence of defects. Indeed, the probability of finding a defect of given size increases with the size of the piece. There are strong fragile size effects.

On the other hand, the constituent materials and the interfaces are exposed to a high temperature gradient, which leads to the degradation of the performance of the modules after consecutive thermal cycles under rupture constraint defined as:

$\sigma=\frac{K_{I C}}{\left(Y \sqrt{\pi a_{\max }}\right)}$

Where $a_{\max }$ is the largest split in the volume considered [13] and for the alumina $K_{I C}=3 \mathrm{MPa} \sqrt{\mathrm{m}}$. So, we find a split in the order of $89.41 \mu \mathrm{m}$ for a rupture constraint of $179 \mathrm{MPa}$.

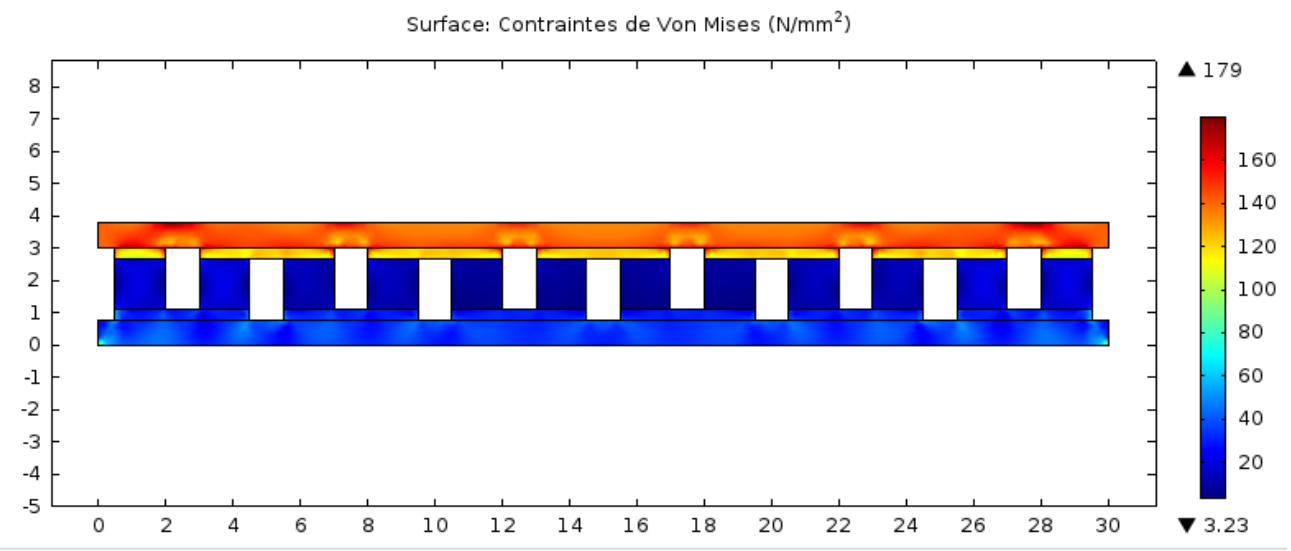

Figure5. Distribution of Von Mises stresses for a single stage model 
Finite Elements Multiphysics Investigation of Thermoelectric Systems for Electricity and Cooling Generation

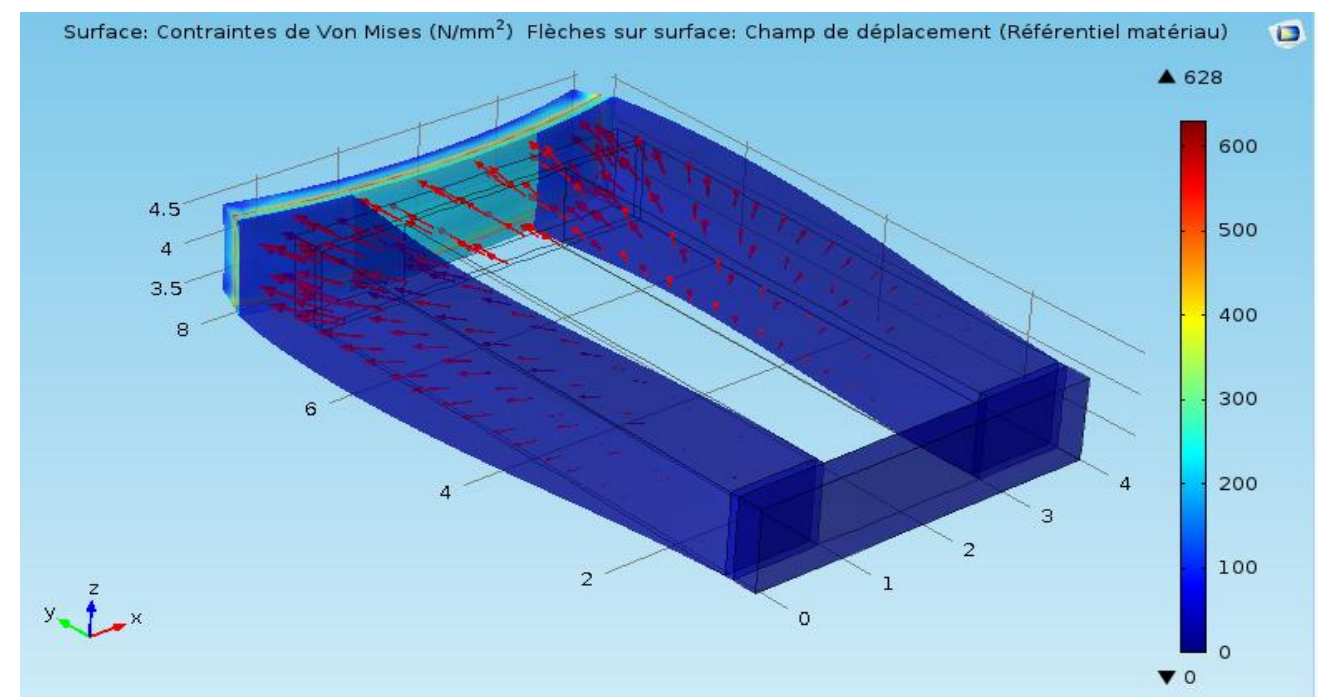

Figure6. Deformation (exaggerated) and Stress displacement field of Von Mises

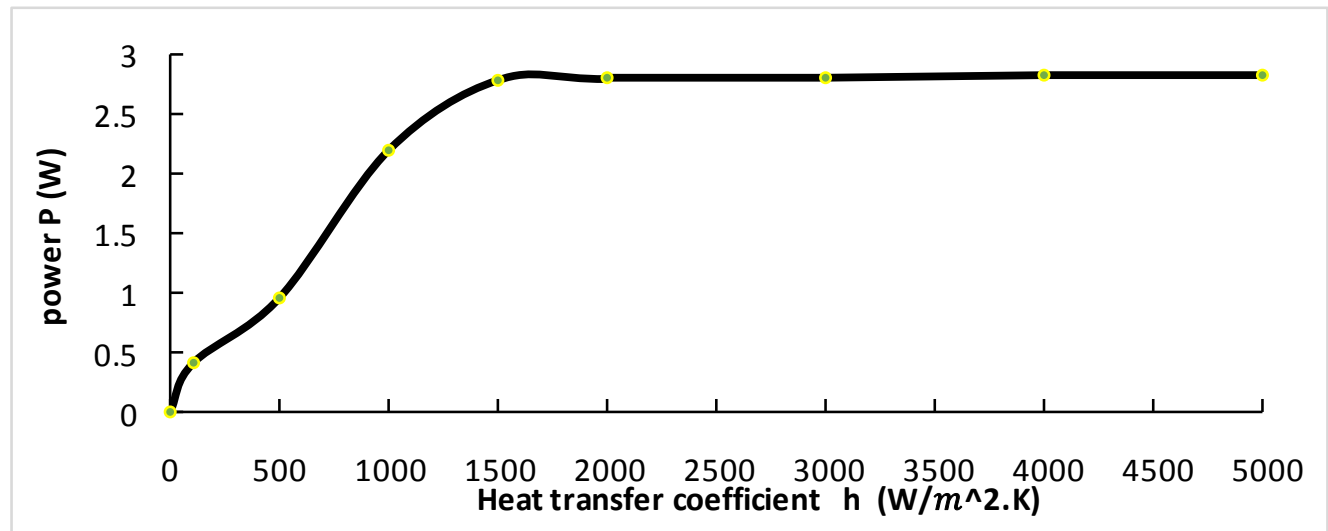

Figure7. Variation of the power as a function of the heat transfer coefficient for a two-legged module

\subsubsection{Variable Heat Transfer Coefficient}

The optimal h value under maximum power was investigated (Figure 7). The same conditions were applied to the model, but instead of constant cold temperature a cooling system was simulated under convective heat flux.

The optimum $\mathrm{h}$ value for these conditions is close to $1500 \mathrm{~W} \cdot \mathrm{m}-{ }^{2} \cdot \mathrm{K}-1$ which is higher than the maximum $\mathrm{h}$ value of air cooling $<300 \mathrm{~W} \cdot \mathrm{m}^{-2}$.K-1. However, this value is in the water cooling range (0.3-6 kW.m-2 $\left.{ }^{2} \mathrm{~K}-1\right)$ for forced convection. For efficient radiative heating, cooling by water becomes necessary to produce electricity more efficiently. For efficient heat transfer, a high cooling of the cold surface is important to generate more efficient TE power even when the heating is of a constant heat flux. Convective $\mathrm{h}$ coefficients for some fluids presented in table 3 may be found in Rowe and Bhandari (1983) [14].

However, water cooling is not desirable because it consumes a lot of energy. Therefore, simple ventilation by air seems to be a good solution for our problem of overheating.

Table3. Convective heat transfer coefficients for a few fluids [12]

\begin{tabular}{|c|c|}
\hline Medium & $h\left(W / m^{2} \cdot K\right)$ \\
\hline Air ( natural convection) & $5-25$ \\
\hline Air / overheated vapor (forced convection) & $20-300$ \\
\hline Oil ( forced convection) & $60-1800$ \\
\hline Water (forced convection) & $300-6000$ \\
\hline Water (boiling) & $3000-60000$ \\
\hline Vapor (in condensation) & $6000-120000$ \\
\hline
\end{tabular}




\subsubsection{Influence of the Length of TE Elements under Constant Heat Flux}

The dimensions of the TEM, more precisely the length of the TE leg, have been modified. Three different lengths were taken: $\mathrm{a}=1.6 \mathrm{~mm}, \mathrm{~b}=3.2 \mathrm{~mm}$ and $\mathrm{c}=4.8 \mathrm{~mm}$ (Fig.8). Where $\Delta \mathrm{T}$ is proportional to the TE leg length. It was found that, in open circuit, the tension increases as the length of the leg increases.

\section{Surface : température $(K)$}

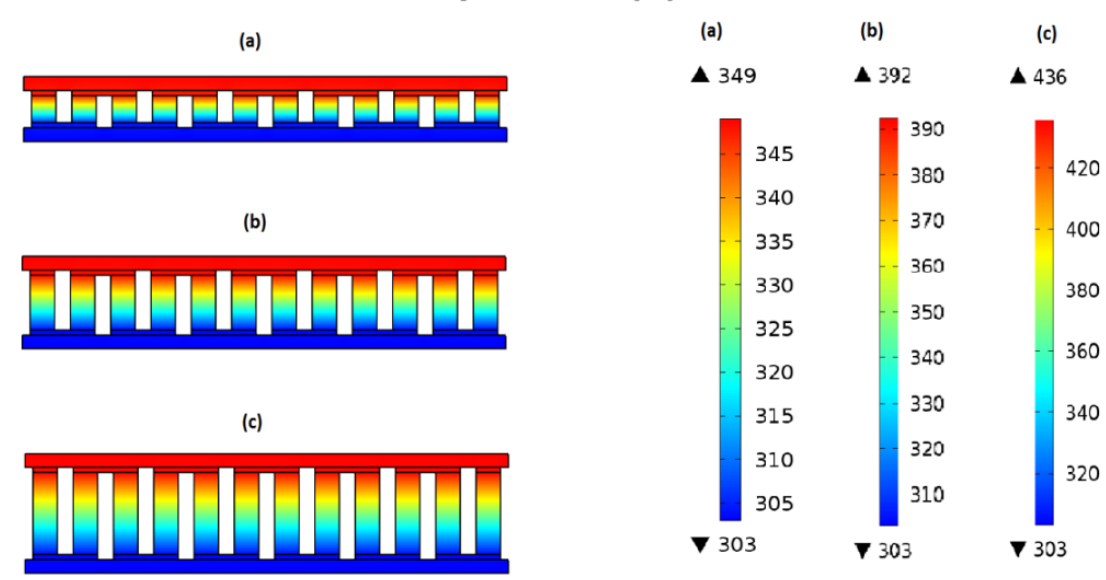

Figure8. Influence of the TE modules length on the temperature distribution

\subsubsection{Influence of Temperature Difference}

The top surface of the TEM module is exposed to solar radiation. This will induce heating of the bottom surface. We want to know the effect of this temperature difference $\Delta T$ on the energy released. At this stage, 44 tests were performed for 4 different current intensities. The voltage (thus the power) was found to increase when $\Delta \mathrm{T}$ increases. The higher value was obtained for a lower cold temperature, thus at a high $\Delta \mathrm{T}$. Thus, an increase of the temperature difference $\Delta \mathrm{T}$ will always lead to an increase of the performances of the module (Figure 9). However, there is a limit to this elevation because at some levels there is a risk of losing energy.

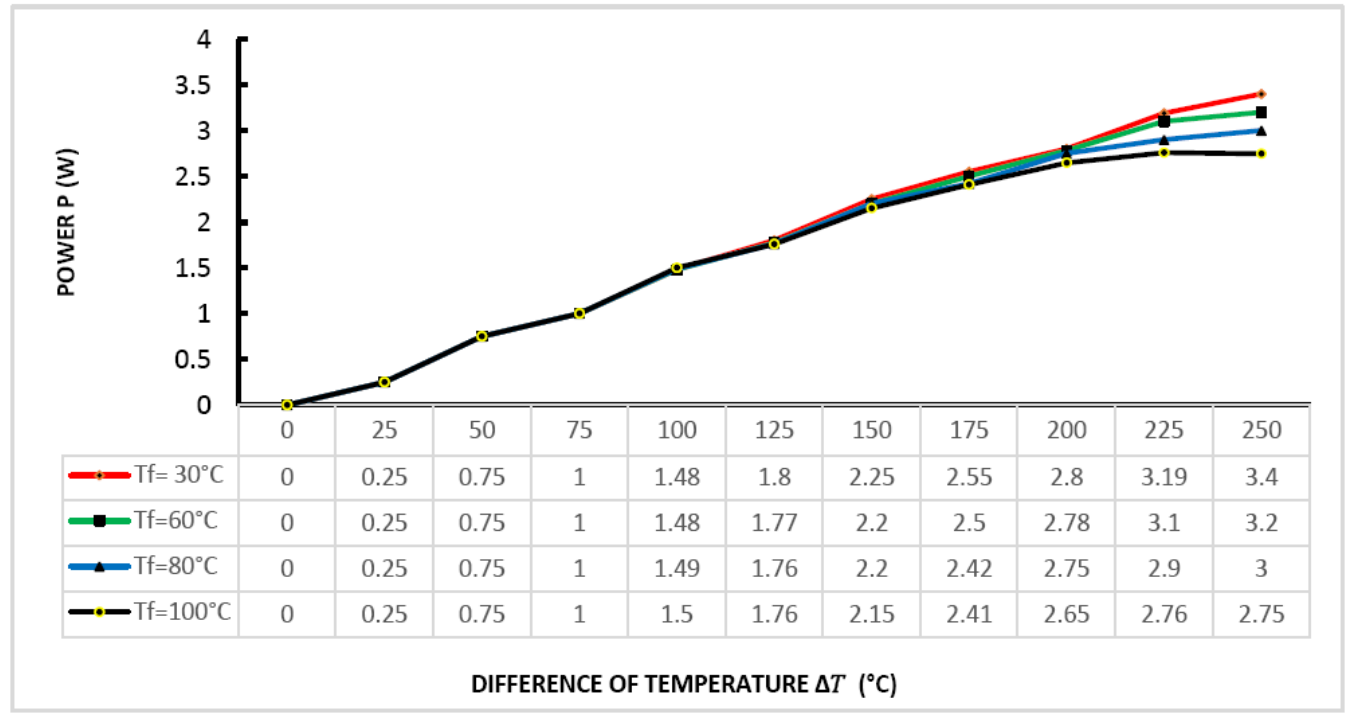

Figure9. Plots of power variation vs the temperature difference

\subsection{Peltier Cooling}

\subsubsection{Cooling Capacity and COP}

The cooling capacity and the coefficient of performance present two important criteria for determining the performance of TEM. In this part, the geometry is parameterized to analyze the effect of its variation. Thus, the influence of the increase in the number of Peltier stages for the cooling of the system is studied (Figure 10). 
The following equations are the equations used in calculation of the COP coefficient $[9,11]$.

$Q_{h}=\alpha \cdot I \cdot T_{h}-R \cdot \frac{I^{2}}{2}+K \cdot\left(T_{h}-T_{c}\right.$

$Q_{c}=\alpha \cdot I \cdot T_{c}-R \cdot \frac{I^{2}}{2}+K \cdot\left(T_{h}-T_{c}\right)$

$P=Q_{h}-Q_{c}=\alpha \cdot I \cdot\left(T_{h}-T_{c}\right)-R \cdot I^{2}$

$\operatorname{COP}=\frac{Q_{c}}{P}=\frac{\left(\alpha_{p}-\alpha_{n}\right) I \cdot T_{c}-K \Delta T-\frac{1}{2} I^{2} R}{I \cdot\left(\left(\alpha_{p}-\alpha_{n}\right) \Delta T+I \cdot R\right.}$

After the calculation for a single-stage TEM, the coefficient of performance was maximum for a current intensity equal to $0.4 \mathrm{~A}$, and that $\mathrm{COP}>0.8$ for a current intensity interval [0.35 A, 0.45A] (Figure 11). The increase in the number of stages resulted in a decrease in the coefficient of performance (Figure 12).

The COP is less than 1 and it decreases progressively when increasing the current intensity. Means that the TEM consumes more electrical energy than it produces; especially at $2.5 \mathrm{~A}$ there is a risk of losing more energy. It is also noted that increasing the number of stages increases the cooling capacity.

The cooling capacity for the three Peltier modules takes an almost constant value up to a current value of $2.5 \mathrm{~A}$. Beyond this value, the cooling capacity decreases progressively by increasing the current intensity (Figure 13).

The thermal management includes a wide range of heating and cooling solutions, as well as components for temperature control. It is proposed here some control techniques to manage the Peltier elements such as heat sinks as well as special combinations between radiator and fan. It is possible to gain energy by taking advantage of the voltage generated by the TEM to supply the fan. For accurate control required during heating or cooling, there is a selection of choices of regulators equipped with different and various features.
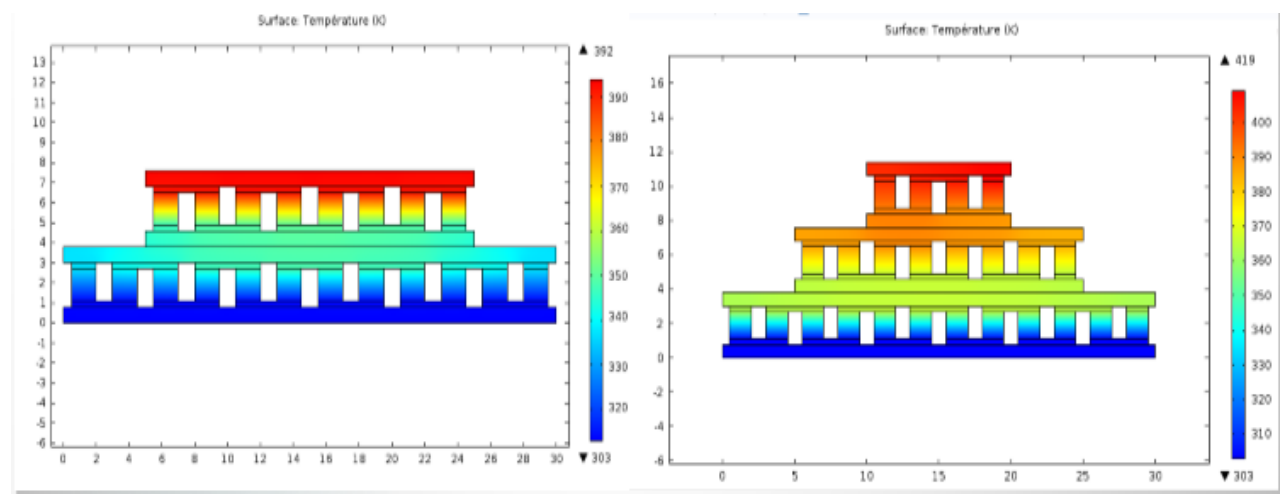

Figure10. Temperature distribution for TEMs in cascade

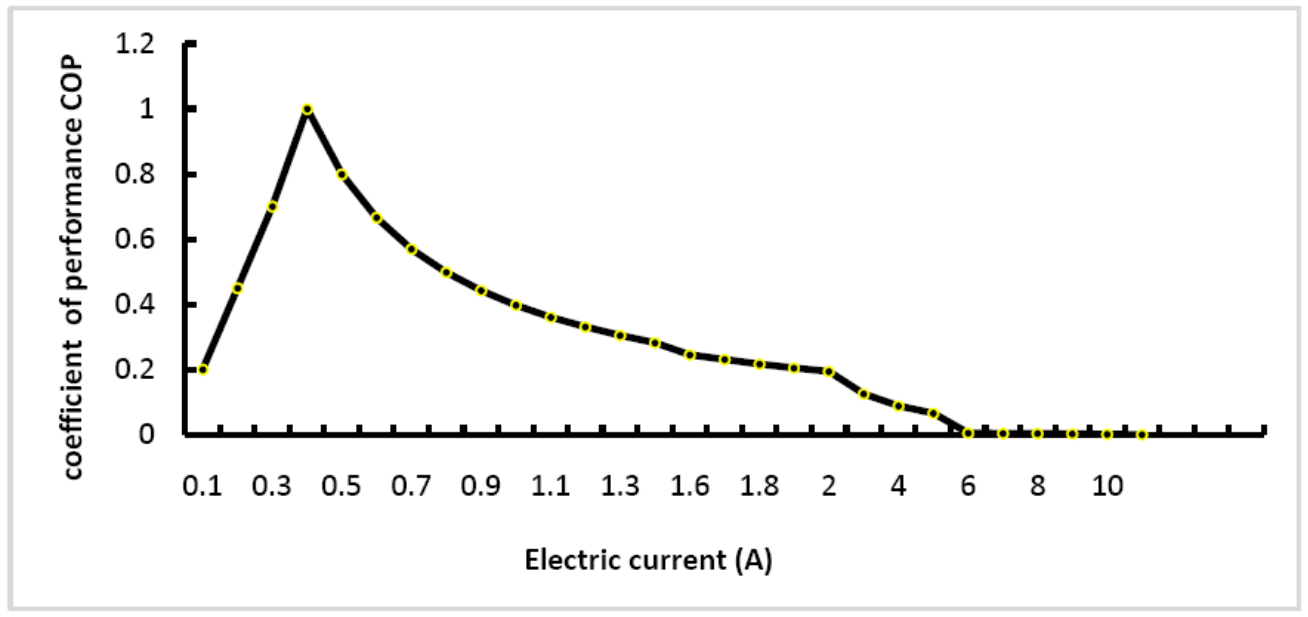

Figure11.Variation of the coefficient of performance as a function of the current for a single stage Peltier 


\subsubsection{Thermal Management}

Thermal management includes a wide range of heating and cooling solutions, as well as components for temperature control. We will propose some control techniques for the control of Peltier elements such as heat sinks as well as special combinations between radiator and fan.

On the other hand, it is possible to gain energy if one takes advantage of the voltage generated by the TEM to supply the fan.

For precise control required during heating or cooling, there is a selection of choices of regulators, which are equipped with different and various features.

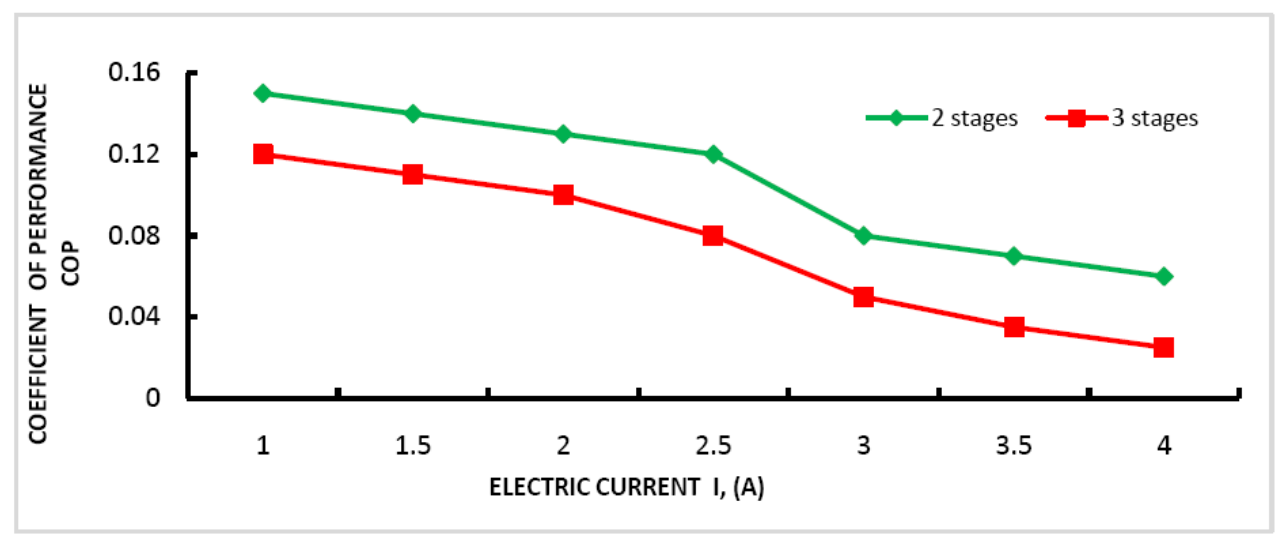

Figure12. Comparison of the modules performance coefficients: 2stages vs 3 stages

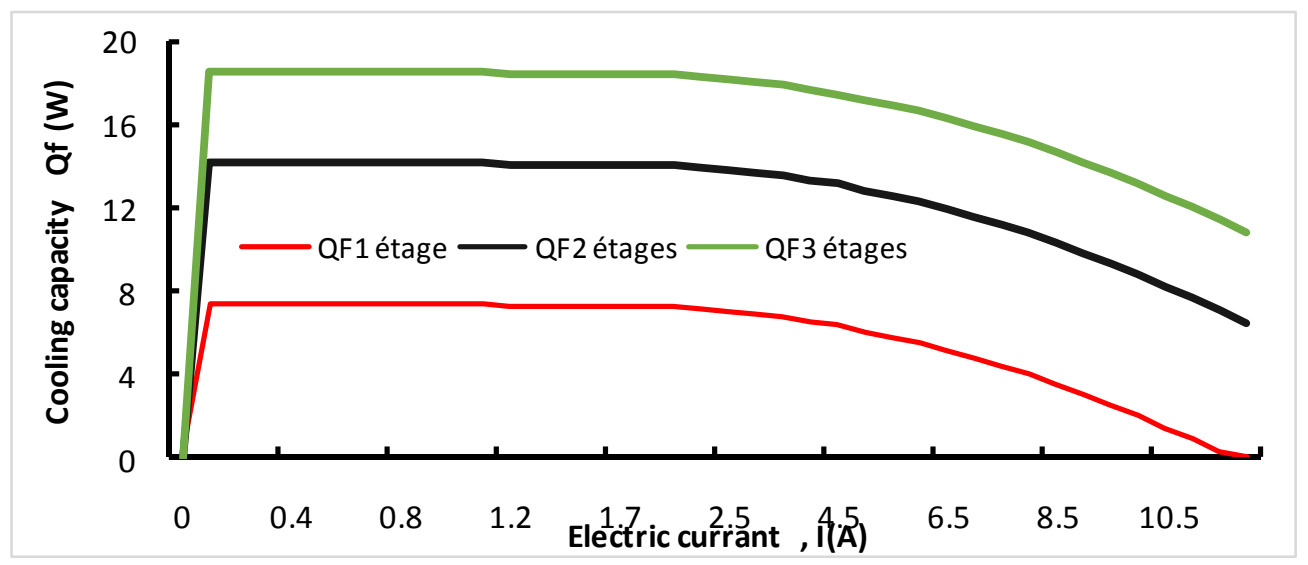

Figure13. Cooling capacity for the three models of Peltier modules

\section{CONCLUSiON}

This work was devoted to a Multiphysics study of modeling and simulation of Peltier cooling and the generation of electricity by TE systems. The model of a solar TEG has been studied using the finite element method under the COMSOL-Multiphysics software and taking into account dependence of the thermo-physical properties of materials as a function of temperature and the influence of several factors Such as the geometry of these modules and thermomechanical constraints. We developed a model to simulate the behavior as a TEG and an analytical method was used to evaluate the energy consumption by cooling the TEG module.

It can be concluded that the design of the TEGs is flexible depending on environmental conditions as reported in several studies and is affected by several parameters, namely the temperature difference and current intensity. Indeed, a TEM thicker can give a higher output power, although the cooling Peltier works to decrease the temperature of the hot junction. When the length of the junction is fixed, it has been found that there is a suitable heat transfer coefficient for obtaining a greater $\Delta \mathrm{T}$ which makes it possible to obtain optimum heat equilibrium between the cooling effect of the hot junctions and the heating effect of the cold junctions and consequently a generation of a higher electrical energy. A large heat transfer coefficient $\mathrm{h}$ can give a higher power, but we risk losing more energy to such a high $\mathrm{h}$ in the cooling fluids. Besides, when three different geometries of the TEG module were 
tested and compared to each other, we have noticed that the power output increases with the increase of the length of the TE leg and consequently the temperature difference between the hot and cold surfaces increases. Moreover, the coefficient of performance and cooling capacity are important to determine the Peltier cooling behavior. Indeed, the increase in the number of stages generates the reduction of the coefficient of performance and increased cooling capacity. This cooling is also appreciated by the fact that it alleviates the TE stresses induced by thermal expansion of materials, one of the objectives of this study.

\section{REFERENCES}

[1] P.S. Rao, N. Sriraj, M. Farookh, Contact Stress Analysis of Spur Gear for Different Materials using ANSYS and Hertz Equation, Int. J. of Modern Studies in Mech. Engineering, 1(1), 2015, pp. 45-52.

[2] S. Kr. Mandal, B. Bhattacharyya, S. Mukherjee, A. Maity, Rotary Tiller's Blade Design using Finite Element Analysis (FEA), Int. J. of Modern Studies in Mech. Engineering, 1(1), 2015, pp. $19-26$.

[3] S.H. Ibrahim, S. H. Ahmed and I.A. Hameed, Evaluated of Mechanical Properties for Aluminum Alloy Using Taguchi Method, Int. J. of Modern Studies in Mech. Engineering, 2(1), 2016, pp. 29-37.

[4] P.S. Rao and Ch.Vamsi, Contact Stress and Shear Stress Analysis of Spur Gear Using ANSYS and Theoretical, Int. J. of Modern Studies in Mech. Engineering, 2(2), 2016, pp. 9-14.

[5] P. Aliabadi, S. Mahmoud and R. K. AL-Dadah. Simulation of cascaded thermoelectric devices for cryogenic medical treatment, Proceedings of the 2014 COMSOL Conference in Cambridge.

[6] R. O. Suzuki, T. FujisaKa, K. O. Ito, X. Meng and H.-T. Sui, Dimensional Analysis of Thermoelectric Modules Under Constant Heat Flux, Journal of Elec Materi: 44, 2015: 348. doi:10.1007/s11664-0143314-z

[7] D. Kraemer, K. McEnaney; M. Chiesa and G. Chen, Modeling and optimization of solar thermoelectric generators for terrestrial applications, Solar Energy: 86, 5, 1338-1350, 2012.

[8] A. ZiABARI, E.SUHIRand A. SHAKOURI, Minimizing thermally induced interfacial shearing stress in a thermoelectric module with low fractional area coverage, Microelectronics Journal:45, 5, 547-553, 2014.

[9] W.H. Chen, C.C. WANG, C. I. Hung, C.C. YANG and R.C. JuAng, Modeling and simulation for the design of thermal-concentrated solar thermoelectric generator, Energy:64, 287-297, 2014.

[10] Wikipedia encyclopedia, https://en.wikipedia.org/wiki/Thermoelectric_effect

[11] M. JAEgLE, Multiphysics Simulation of Thermoelectric Systems, "Modeling of Peltier Cooling and Thermoelectric Generation" Proc. COMSOL Conf. 2008 Hanover, 2008.

[12] Module Peltier GM200-71-14-16 http://uk.rs-online.com/web/p/peltier-modules/6937030/

[13] J. Besson, Endommagement et rupture, Chap. 23, p. 205.

[14] D. M. Rowe and C.M. Bhandari, Modern Thermoelectrics, Reston Publishing Company, 1983 Thermoelectric apparatus and appliances - 157 pages.

\section{ACKNOWLEDGEMENTS}

This paper has been revised, finalized and submitted at the end of scientific stay SSHN2017 $\mathrm{n}$. 903770E financed by Campus France and the ISLAIB-University of Jendouba.

\section{AUTHORS' BIOGRAPHY}

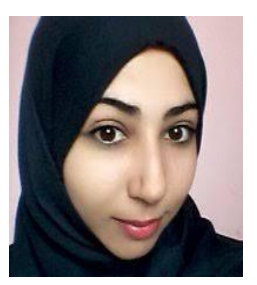

Wiem Nasri, is a Master degree student. She is Engineer in mechanical engineering from High Engineering School of Medjez el Bab (ESIM, Tunisia) on 2015. She is interested to study problems coupling mechanical, material, thermal and electrical fields, such as thermo-electro-mechanical systems, drying problems.

Ridha Djebali, is of Engineer degree in General Mechanical Engineering, of Master's Degree in App. Mechanics of Fluids Heat Transfers, Doctor in Ceramic Materials and Surface Treatments (Univ. of Limoges- France) and HDR in Physical Sciences from the University of Jendouba. His Research topics include, but not limited to: Problems CFD and CHT in free and porous media / Thermal spraying processes and plasma jets dynamics,/ Taguchi Experimental Design / Heat transfer enhancement by nanofluids / Numerical simulation and modeling using Lattice Boltzmann method (LBM) \& Finite Volumes (FVM), Fire Dynamics Simulator (FDS), Fluent and COMSOL multiphysics. 


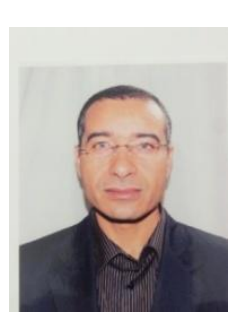

Samir Dhaoui, is Engineer in electrical engineering (Industrial electricity). He is a teacher at the Higher Institute of technological Studies (ISET) of Béja, Tunisia and has the rank of associate Professor Techologist. His researches focus on renewable energy especially in photovoltaic energy.

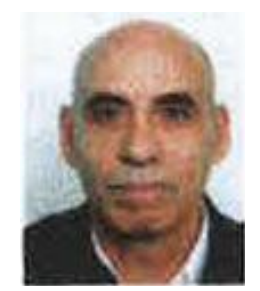

Said Abboudi, is Professor UTBM and responsible for the research theme: Thermophysical Couplings and Optimization of Thermal Systems. He is interested in studying problems of: Modeling in mechanics and thermals, conduction and convection inverse, thermomechanical coupling, heat and mass transfer, with applications to heat exchangers, thermal barrier, renewable energy, solidification, fuel cells. He has supervised more than 20 thesis and more than 6 masters. He taught heat and mass transfer modeling courses, systems analysis and optimization, inverse methods in thermal, numerical methods in fluid mechanics, optimization of thermal systems and was responsible for several administrative activities.

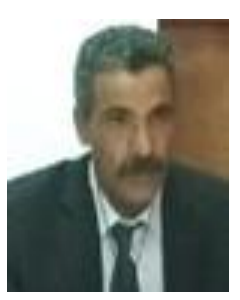

Hassan Kharroubi, is Professor in Mechanical Engineering at the High Engineering School of Medjez el Bab (ESIM, Tunisia) and its Director. He is interested in studying many problems of hydro-thermomechanical fields. He taught courses of general mechanics and mechanical systems for engineering student degrees and was responsible for several administrative activities.

Citation: R. Djebali et al. (2017). Finite Elements Multiphysics Investigation of Thermoelectric Systems for Electricity and Cooling Generation, International Journal of Modern Studies in Mechanical Engineering (IJMSME), 3(4), pp.1-13, DOI: http://dx.doi.org/10. 20431/2454-9711.0304001.

Copyright: () 2017 R. Djebali. This is an open-access article distributed under the terms of the Creative Commons Attribution License, which permits unrestricted use, distribution, and reproduction in any medium, provided the original author and source are credited 